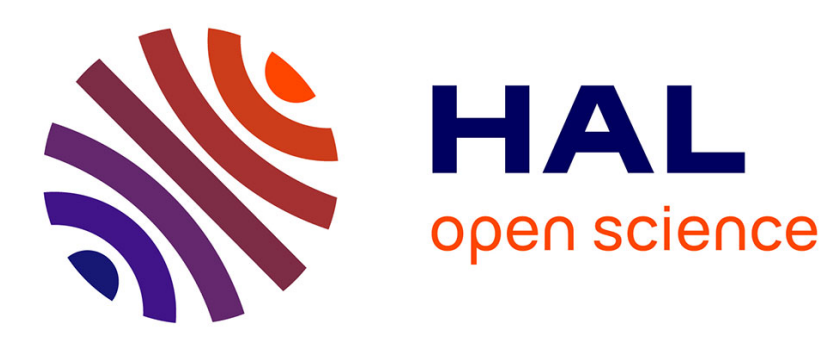

\title{
Stability, spectra and structure of the copper(II) chloride complexes in acetic acid.
}

Mustayeen A. Khan, J. Meullemeestre, M.J. Schwing, F. Vierling

\section{To cite this version:}

Mustayeen A. Khan, J. Meullemeestre, M.J. Schwing, F. Vierling. Stability, spectra and structure of the copper(II) chloride complexes in acetic acid.. Polyhedron, 1983, 2 (6), pp.459-463. 10.1016/S02775387(00)87093-X . hal-03163593

\section{HAL Id: hal-03163593 \\ https://univ-angers.hal.science/hal-03163593}

Submitted on 10 Mar 2021

HAL is a multi-disciplinary open access archive for the deposit and dissemination of scientific research documents, whether they are published or not. The documents may come from teaching and research institutions in France or abroad, or from public or private research centers.
L'archive ouverte pluridisciplinaire HAL, est destinée au dépôt et à la diffusion de documents scientifiques de niveau recherche, publiés ou non, émanant des établissements d'enseignement et de recherche français ou étrangers, des laboratoires publics ou privés. 


\title{
STABILITY, SPECTRA AND STRUCTURE OF THE COPPER(II) CHLORIDE COMPLEXES IN ACETIC ACID
}

\author{
M. A. KHAN, J. MEULLEMEESTRE, M. J. SCHWING and F. VIERLING* \\ E.N.S.C.S., Laboratoire de Chimie Physique ERA No. 166 1, rue Blaise Pascal, 67008 Strasbourg, France
}

(Received 5 July 1982)

\begin{abstract}
The stability constants and the electronic spectra of four molecular chlorocomplexes formed in acetic acid solutions have been calculated. The spectrophotometric measurements were performed at wavelengths ranging from 260 to $500 \mathrm{~nm}$ and, in the near IR from 600 to $1400 \mathrm{~nm}$. The matrix rank treatment of more than 1000 spectrophotometric data demonstrates a minimum of five absorbing species: the solvated copper(II) acetate and four chlorocomplexes. The overall stability constants of $\mathrm{Cu}(\mathrm{OAc}) \mathrm{Cl}, \mathrm{CuCl}_{2}, \mathrm{LiCuCl}_{3}$ and $\mathrm{LiCuCl}_{4}$ are respectively: $\log \beta_{1}=3.38 ; \log \beta_{2}=5.57 ; \log \beta_{3}=7.36 ; \log \beta_{4}=7.83$. The structure of the monochlorocuprate with the $\mathrm{Cu}-\mathrm{OAc}$ bonding in the primary coordination sphere is supported by near-IR evidence. The bathochromic shift of the absorption maxima of the $d-d$ transition bands indicates structural changes of the complexes with a square planar configuration for $\mathrm{Cu}(\mathrm{OAc}) \mathrm{Cl}$ promoted to a flattened tetrahedron for $\mathrm{Li}_{2} \mathrm{CuCl}_{4}$.
\end{abstract}

An exhaustive study of the copper(II) chloride complexes in aqueous solution was carried out by Schwing and $\mathrm{Khan}^{1.2}$ who concluded the presence of four mononuclear successive complexes, calculated their equilibrium constants and discussed briefly the structure of the $\mathrm{CuCl}_{4}{ }^{2-}$ ion in aqueous solution. The emphasis now seems to have shifted to the study of these copper(II) chlorocomplexes in nonaqueous solutions. This is mainly because of very small values of the overall equilibrium constants, $\beta_{j}$, in water, in contrast to their very high values in nonaqueous solvents. Moreover in water there is an overlapping of the characteristic bands of the complexes, which are well separated in the latter solvents.

Furlani and Morpurgo ${ }^{3}$ suggest a flattened tetrahedral $\left(D_{2 d}\right.$ symmetry) structure for tetrachlorocuprates after studies in solid state and such organic solvents as acetonitrile, nitromethane, ethylalcohol, dimethylformamide (DMF) and dimethylsulphoxide ( $\left.\mathrm{Me}_{2} \mathrm{SO}\right)$. Manahan and Iwamoto ${ }^{4}$ have proposed very high values for the equilibrium constants of $\mathrm{CuCl}^{+}$and $\mathrm{CuCl}_{2}$ in acetonitrile.

Gutman et al. have shown spectrophotometrically the existence of four chlorocomplexes in $\mathrm{DMF}^{5}$ in acetonitrile and in trimethylphosphate ${ }^{6}$ at the same time postulating a very small equilibrium constant for $\mathrm{CuCl}_{2}$. On the other hand Courtot et al. ${ }^{7}$ using potentiometric and spectrophotometric means propose three copper(II) chlorocomplexes, $\mathrm{CuCl}^{+}, \mathrm{CuCl}_{2}, \mathrm{CuCl}_{3}{ }^{-}$in $\mathrm{Me}_{2} \mathrm{SO}$. Scharff as also proposed the existence of these complexes in propylene carbonate. ${ }^{8}$

Very recent work published from our laboratory confirms the presence of three complexes postulated by Gutman et al. in DMF but with $\mathrm{CuCl}^{+}, \mathrm{CuCl}_{3}{ }^{-}$and $\mathrm{CuCl}_{4}{ }^{2 \cdots} .9$ The absence of the dichlorocomplex in this model is due to similar solvent and ligand donor numbers, inducing dissociation of $\mathrm{CuCl}_{2}$ and autocomplex formation of $\mathrm{CuCl}^{+}$and $\mathrm{CuCl}_{3}{ }^{-10}$ The same $[1,3,4]$ model, i.e. $\mathrm{CuCl}^{+}, \mathrm{CuCl}_{3}{ }^{-}$and $\mathrm{CuCl}_{4}{ }^{2-}$ is found in

${ }^{*}$ Author to whom correspondence should be addressed.
$\mathrm{Me}_{2} \mathrm{SO}$ instead of [1-3], i.e. $\mathrm{CuCl}^{+}, \mathrm{CuCl}_{2}$ and $\mathrm{CuCl}_{3}{ }^{-}$ suggested in $\mathrm{Ref}^{7}$, but the [1-4] model, i.e. $\mathrm{CuCl}^{+}$, $\mathrm{CuCl}_{2}, \mathrm{CuCl}_{3}{ }^{-} \mathrm{CuCl}_{4}{ }^{2-}$ is clearly established in propylene carbonate ${ }^{11}$ against the unsatisfactory [1-3] proposed in the same medium by Scharff. ${ }^{8}$

Beside these dissociating solvents, the non-dissociating acetic acid has also been used for the study of the copper(II) chlorocomplexes. Eswein et al. ${ }^{12}$ suggest an equilibrium between the $D_{4 h}$ (square planar) and $D_{2 d}$ symmetry species for the tetrachlorocomplex in acetic acid, assigning the peak at $450 \mathrm{~nm}$ to $D_{2 d}$ and that at $375 \mathrm{~nm}$ to $D_{4 h}$ configuration. They identify the absorption maximum at $670 \mathrm{~nm}$ as that of cupric acetate in acetic acid but it is surprising that they do not observe any isosbestic point.

Sawada et al. have studied in detail the equilibria of copper(II) acetate in acetic acid with perchloric acid and lithium acetate ${ }^{13}$ and with hydrochloric acid and copper(II) chloride. ${ }^{14}$ They suggest that the characteristic absorption maximum of copper acetate in acetic acid is at $685 \mathrm{~nm}$ and observe isosbestic points at 360 and $440 \mathrm{~nm}$ and postulate the presence of tri- and tetrachlorocomplexes. However their work is limited to the interpretation of data obtained only at two wavelengths.

This work pertains to the formation of copper(II) chlorocomplexes in acetic acid at $25^{\circ} \mathrm{C}$. The number of complexes present in the solution and their equilibrium constants were determined after a spectrophotometric study in the UV and visible region, from 270 to $500 \mathrm{~nm}$ and in the near-IR from 600 to $1400 \mathrm{~nm}$. A quantitative interpretation of the whole spectrum (UV, vis., IR) was undertaken. All data were taken into account to calculate the equilibrium constants and the variation of the extinction coefficients of the individual copper(II) chlorocomplexes. Tests for different models of complexes present in the solution were performed in accordance with the results of the matrix rank method, mentioned in our discussion.

\section{EXPERIMENTAL}

Anhydrous acetic acid, pro analysis (Merck) was used after adding calculated amount of acetic anhydride, p.a. (Merck), with the addition of three drops of $0.001 \mathrm{M}$ perchloric acid, $70 \%$ p.a. 
(Merck) and letting the solution stand overnight. ${ }^{15}$ Copper solutions were prepared from a stock solution of copper(II) acetate, p.a. (Merck). Lithium chloride p.a., (Merck) was used without any purification.

The final analytical concentration of copper was $5 \times 10^{-4} \mathrm{M}$ for measurements in UV-vis. and $3.75 \times 10^{-3} \mathrm{M}$ in IR region. In these spectrum regions chloride concentrations were varied from $5 \times$ $10^{-4}$ to $1 \mathrm{M}$, with $l=0.5 \mathrm{~cm}$, and from $2.5 \times 10^{-3}$ to $1 \mathrm{M}$, with $l=2 \mathrm{~cm}$, respectively.

Acetic acid was the spectrophotometric reference solution. The final solutions of copper and chloride were prepared just before the measurements. The optical densities were obtained with a CARY 17D instrument with digital interfacing and a Periferic Zip 30 rapid printer and puncher. The numerical analysis was performed on a UNIVAC 1110 computer.

\section{RESULTS AND DISCUSSION}

Acetic acid is a molecular solvent, its dielectric constant being 6.2, and therefore non-ionic in character. However two series of measurements were carried out. One with lithium perchlorate to keep the molecular environment constant and equal to $1 \mathrm{M}$ and the other, without lithium perchlorate. The absorption spectra of the two series in UV, visible and IR being identical, the simpler of the two equilibria, i.e. the direct mixing of copper(II) acetate and lithium chloride solutions was retained for the study.

(a) Spectra of copper(II) chloride in acetic acid

When chloride is added to the copper(II) solution in acetic acid the colour changes from blue to greenish yellow, and eventually to bright yellow with the increase in chloride concentration. The absorption variations with respect to the chloride concentration in UV, visible and IR are presented in Fig. 1.

The free solvated copper(II) acetate has an absorption maximum at about $252 \mathrm{~nm}$. The addition of chloride shows the formation of a peak at $300 \mathrm{~nm}$ which undergoes a hypsochromic effect as the chloride concentration increases with a shift to $280 \mathrm{~nm}$. This maximum is not
Gaussian suggesting a superposition of two maxima. For chloride concentrations much higher than $0.02 \mathrm{M}$ there appears a maximum at $445 \mathrm{~nm}$ and for concentrations higher than $0.05 \mathrm{M}$ another at $380 \mathrm{~nm}$. These two maxima coalesce at $385 \mathrm{~nm}$ at still higher concentrations. Three isobestic points are observed at 302,357 and $437 \mathrm{~nm}$. Sawada et al. ${ }^{14}$ have reported only two isobestic points at 360 and $440 \mathrm{~nm}$ whereas the work of Eswein et al. is conspicuous by its statement that "no isobestic points are observed". It is to be remarked that this latter work was carried out by preparing chloride solutions by dissolving the chloride salt first in small quantity of water before adjusting the volume with acetic acid. In our case it was observed that the addition of small quantities of water has a profound effect on the complexation, a few drops being sufficient to render the solution colourless from greenish yellow or bright yellow. This aquation effect has also been noted by Sawada and Tanaka. ${ }^{16}$

In the IR region the characteristic maximum of copper(II) acetate in acetic acid is observed at $680 \mathrm{~nm}$ $\left(198 \mathrm{M}^{-1} \mathrm{~cm}^{-1}\right)$. This peak which has been variously reported at $650^{15}, 670^{12}$ and $685 \mathrm{~nm}^{14}$ disappears as the chloride concentration increases and shifts to $1060 \mathrm{~nm}$. This shift of $380 \mathrm{~nm}$ of the solvated copper(II) ion in acetic acid, from 680 to $1060 \mathrm{~nm}$, is remarkably similar to the bathochromic shift in DMF, ${ }^{9}$ propylene carbonate and $\mathrm{Me}_{2} \mathrm{SO}^{11}$

\section{(b) Equilibrium in solution}

Copper(II) acetate in acetic acid has been reported to have a maximum at $365 \mathrm{~nm}$ which has been ascribed to copper-copper bond by Yamada et al. ${ }^{17}$ and Martin and Whitley, ${ }^{18}$ indicating that the salt is dimerised in solution. This is confirmed by Sawada ${ }^{13}$ who has located this maximum at $370 \mathrm{~nm}$. This maximum although not visible in our work because of low copper concentration in UVvisible, appears distinctly at $375 \mathrm{~nm}$ with copper concentration $3.75 \times 10^{-3} \mathrm{M}$. In view of this and the fact that acetic acid being a non-dissociating solvent, molecular

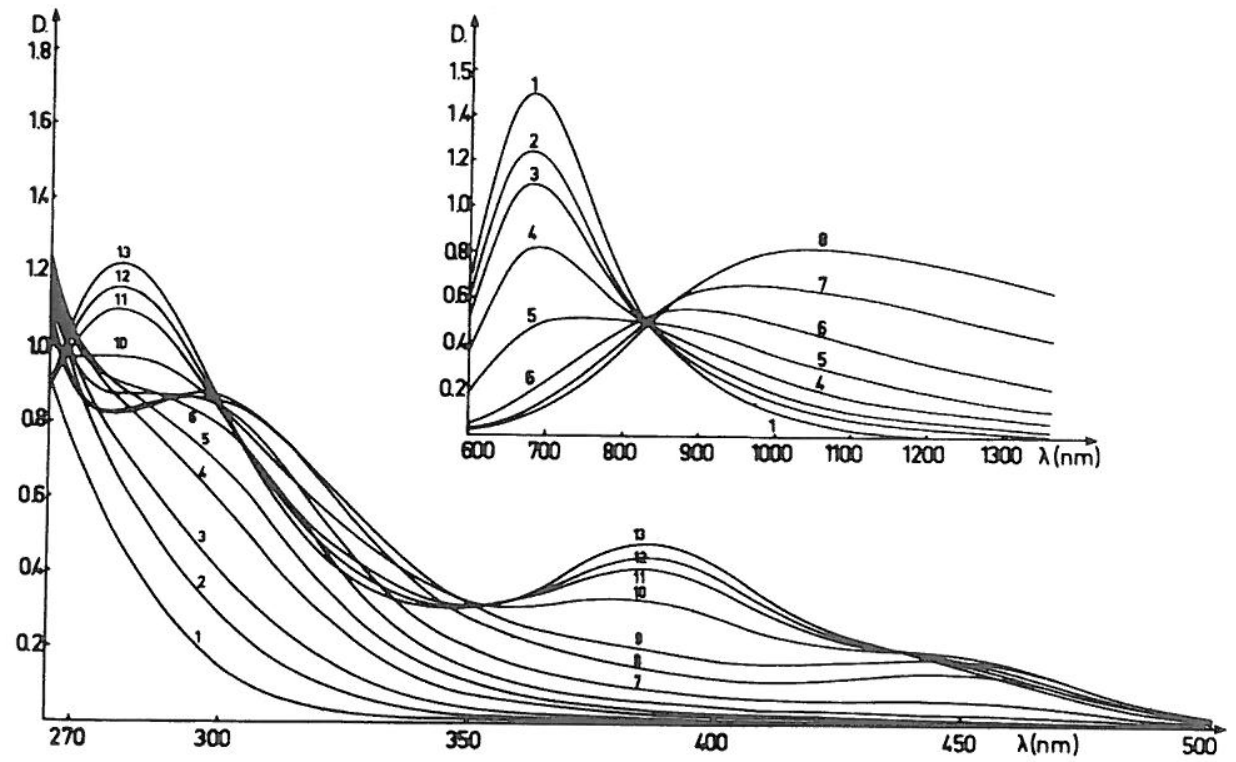

Fig. 1. Experimental spectra of copper(II) chloride solutions: spectrum $/ 10^{3} \times\left[\mathrm{Cl}^{-}\right]_{\text {anal. }}$ UV-visible: $\left[\mathrm{Cu}(\mathrm{OAc})_{2}\right]_{\text {anal }}=$

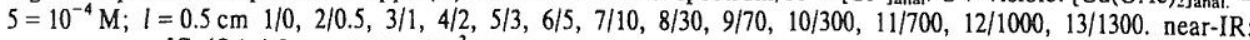

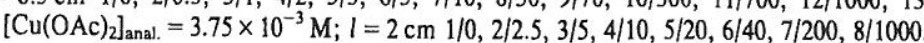


association occurs and the following equilibria are proposed:

$$
\begin{aligned}
& \mathrm{Cu}_{2}(\mathrm{OAc})_{4}+2 \mathrm{LiCl} \rightleftharpoons 2 \mathrm{CuCl}(\mathrm{OAc}), 2 \mathrm{LiOAC} \\
& \mathrm{Cu}_{2}(\mathrm{OAc})_{4}+4 \mathrm{LiCl} \rightleftharpoons 2 \mathrm{CuCl}_{2}, 4 \mathrm{LiOAc} \\
& \mathrm{Cu}_{2}(\mathrm{OAc})_{4}+6 \mathrm{LiCl} \rightleftharpoons 2 \mathrm{CuCl}_{3} \mathrm{Li}, 4 \mathrm{LiOAc} \\
& \mathrm{Cu}_{2}(\mathrm{OAc})_{4}+8 \mathrm{LiCl} \rightleftharpoons 2 \mathrm{CuCl}_{4} \mathrm{Li}_{2}, 4 \mathrm{LiOAc} .
\end{aligned}
$$

The copper(II) acetate has a dimeric structure in acetic acid but the copper(II) chlorocomplexes are monomeric. ${ }^{14}$ The formulation of the monochlorocomplex as $\mathrm{Cu}(\mathrm{OAc}) \mathrm{Cl}$ is supported by the near-IR evidence and is discussed further on.

\section{(c) Experimental data and numerical analysis}

The optical density variations as a function of chloride concentration were plotted from 260 to $500 \mathrm{~nm}$, at intervals of $10 \mathrm{~nm}$. These plots were used to obtain $\mathrm{N}$ optical density values for each selected wavelength for computation. Eventually a set of 24 wavelengths in the UV-visible range with $\mathrm{N}=28$ for each wavelength were considered. In the near IR region 20 wavelengths, from 600 to $1400 \mathrm{~nm}$, at intervals of $40 \mathrm{~nm}$, with $\mathrm{N}=24$ for each wavelength, were taken into account.

A matrix rank treatment method was performed for determining the minimum number of absorbing species present in the solution ${ }^{19}$ which requires a set of $\mathrm{N} \times \mathrm{L}$ data, where $\mathrm{N}$ is the number of solutions and $\mathrm{L}$ the number of wavelengths, with $\mathrm{N}$ imperatively greater than L. The interpretation of 1152 spectrophotometric data indicated a minimum of four species: the solvated copper(II) acetate and at least three copper(II) chlorocomplexis.

\section{(d) Calculated models and equilibrium constants}

The theoretical expressions and the mathematical treatment has been explained in our earlier publication. ${ }^{9}$ The computation was performed at three different mononuclear complexes models: the [1-3], the [1, 3, 4] and the $[1-4]$ model in accordance with the matrix rank analysis results. Table 1 summarises the results of the numerical analysis of the three different models:

The quadratic mean, $\sigma$, for the first two models has a value of 0.128 and 0.130 respectively. On the other hand a far better value of $\sigma=0.054$ is obtained for the model [1-4]. Consequently the existence of four mononuclear successive complexes is proposed in acetic acid for copper(II) chloride solutions.

The stability of the complexes is much higher than in water but comparable to that found in other solvents such as $\mathrm{DMF}^{9}$ or $\mathrm{Me}_{2} \mathrm{SO}:{ }^{11}$ despite the different associative property of these solvents this is particularly true for the overall stability constant of the monochlorocom- plex and the stepwise formation constant of the tetrachlorocomplex. On the contrary, very higher $\beta_{j}^{\prime}$ s were calculated in the propylene carbonate solutions for an identical [1-4] model: the associative solvent effect, predicted by the very low dielectric constant of acetic acid $(\epsilon=6)$ compared to that of propylene carbonate $(\epsilon=69)$ should be one of the' factors which supports these stability differences.

Incomplete formation for each of the four species, represented in Fig. 3, is found in the acetic acid system, which render impossible the $\beta_{i}$ determination of one separated species and explain the drastic higher value found by Sawada et al. for $\mathrm{CuCl}_{2}\left(\log \beta_{2}=15.2\right) .{ }^{14}$ These authors used data at $300 \mathrm{~nm}$ where they do not observe any further shift of the absorption with ligand concentration increase: consequently they postulate the unique presence of $\mathrm{Cu}(\mathrm{OAc}) \mathrm{Cl}$ and $\mathrm{CuCl}_{2}$. As a matter a fact, at $300 \mathrm{~nm}$ the absorption maximum does not change with higher chloride concentration as seen in our experimental spectra of Fig. 1. But other absorption maxima appear, particularly at 280 and $385 \mathrm{~nm}$ with chloride ligand in. crease, which is obviously consistent with the presence of one or two other complexes. The individual electronic spectra calculation shown next in Fig. 2 indicate clearly that the extinction coefficients of $\mathrm{LiCuCl}_{3}$ and $\mathrm{Li}_{2} \mathrm{CuCl}_{4}$ cannot be neglected at $300 \mathrm{~nm}$.

On the other hand, we found stepwise formation constants $\mathrm{K}_{3}$ and $\mathrm{K}_{4}$ very similar $(1.78$ and 0.45$)$ to those calculated by Sawada et al. ${ }^{14}$ (1.68 and -0.15$)$ using data at 385 and $450 \mathrm{~nm}$ : at those wavelengths the absorption due to $\mathrm{Cu}(\mathrm{OAc}) \mathrm{Cl}$ and $\mathrm{CuCl}_{2}$ are effectively neglegeable compared to those of $\mathrm{LiCuCl}_{4}$ (Fig. 2). Another evidence for the unique presence of the latter complexes involves the presence of isobestic points at 302,357 and $437 \mathrm{~nm}$. But once again, the discussion shows the necessity to use absorption data over the whole wavelengths range for a precise determination of the best model and accurate stability constants values.

\section{(e) Electronic spectra of the copper(II) chlorocomplexes} in acetic acid

The electronic spectra of the individual chlorocomplexes for the [1-4] model in the UV, visible and the near IR are presented in Fig. 2.

Monochlorocomplex, $\mathrm{CuCl}(\mathrm{OAc})$. In the near IR there is a peak at $680\left(1970 \mathrm{M}^{-1} \mathrm{~cm}^{-1}\right)$ which is obviously due to the acetate ion associated with the complex. This transition is clearly characteristic of the copper-acetate bond as it is located at the same wavelength as that observed for the copper(II) acetate solution, with a comparable extinction coefficient $(680 \mathrm{~nm}-$ $198 \mathrm{M}^{-1} \mathrm{~cm}^{-1}$; spectrum 1-Fig. 1). Therefore the formulation of the monochlorocomplex is proposed as

Table 1. Results of the numerical analysis of the theoretical models for the acetic acid-copper(II) chloride solutions

\begin{tabular}{lccc}
\hline & {$[1,2,3]$} & {$[1,3,4]$} & {$[1,2,3,4]$} \\
\hline $\log \beta_{1}$ & 3.20 & 8.97 & 3.38 \\
$\log \beta_{2}$ & 5.66 & - & 5.57 \\
$\log \beta_{3}$ & 7.46 & 14.26 & 7.36 \\
$\log \beta_{4}$ & - & 15.93 & 7.83 \\
$\sigma$ (uv-vis) & 0.128 & 0.130 & 0.054 \\
\hline
\end{tabular}




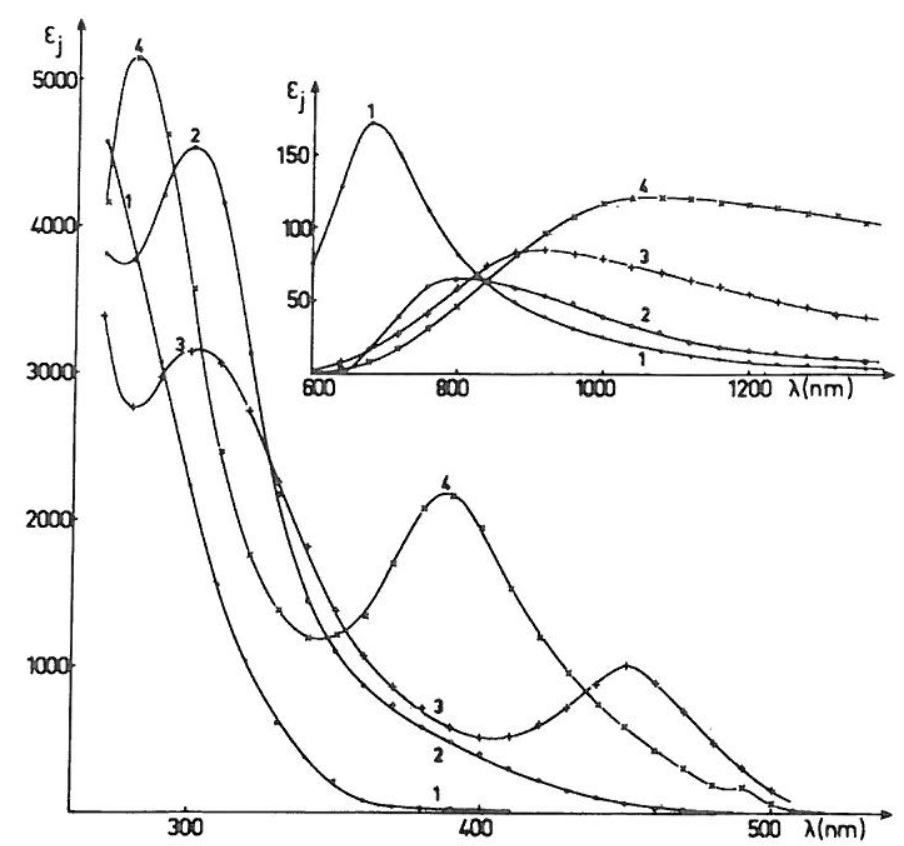

Fig. 2. Calculated electronic spectra of the copper(II) chlorocomplexes in acetic acid.

$\mathrm{CuCl}(\mathrm{OAc})$. This complex may also present a maximum at $260 \mathrm{~nm}$ as in water ${ }^{2}$ and DMF. ${ }^{9}$ Unfortunately this absorption maximum could not be ascertained because of absorption interference due to solvent below $270 \mathrm{~nm}$.

It may be pointed out here that copper acetate was used instead of copper perchlorate because with the latter, at copper concentrations greater than $10^{-3} \mathrm{M}$ precipitation occurs for higher chloride concentration, especially in the presence of lithium perchlorate. Had copper perchlorate been used it would have rendered difficult the exploration of the spectrum in the near IR region where, for copper concentration less than $10^{-3} \mathrm{M}$ the absorption is very low.

Dichlorocomplex, $\mathrm{CuCl}_{2}$. The absorption maximum of this complex is centred at $300 \mathrm{~nm}\left(455 \mathrm{M}^{-1} \mathrm{~cm}^{-1}\right)$ in the UV region and can be compared to that at $315 \mathrm{~nm}$ in propylene carbonate. In the IR, $\mathrm{CuCl}_{2}$ has a $\lambda_{\max }=$ $800 \mathrm{~nm}\left(65 \mathrm{M}^{-1} \mathrm{~cm}^{-1}\right)$.

Trichlorocomplex, $\mathrm{CuCl}_{3} \mathrm{Li}$. It presents three maxima, one each in UV, visible and IR, at $300\left(3150 \mathrm{M}^{-1} \mathrm{~cm}^{-1}\right)$, $450\left(900 \mathrm{M}^{-1} \mathrm{~cm}^{-1}\right)$ and $910 \mathrm{~nm}\left(85 \mathrm{M}^{-1} \mathrm{~cm}^{-1}\right)$. The peaks in UV and visible are comparable to those in DMF and $\mathrm{Me}_{2} \mathrm{SO}$, but differ by $20 \mathrm{~nm}$ from those in propylene carbonate.

Tetrachlorocomplex, $\mathrm{CuCl}_{4} \mathrm{Li}_{2}$. The tetrachlorocomplex has an intense absorption maximum at $280 \mathrm{~nm}$ $\left(5160 \mathrm{M}^{-1} \mathrm{~cm}^{-1}\right)$ and another at $388 \mathrm{~nm}\left(2170 \mathrm{M}^{-1} \mathrm{~cm}^{-1}\right)$. These two bands, with slight differences, have been widely reported in many previous works. It is probable that the differences in the position of these bands are due to different solvents used in each work. There seems to be another hidden band of feeble intensity at $490 \mathrm{~nm}$ $\left(180 \mathrm{M}^{-1} \mathrm{~cm}^{-1}\right)$. In the IR the tetrachlorocomplex peaks out at $1080 \mathrm{~nm}\left(120 \mathrm{M}^{-1} \mathrm{~cm}^{-1}\right)$.

\section{(f) Isosbestic points}

A very good harmony is noted between experimental and calculated isosbestic points.

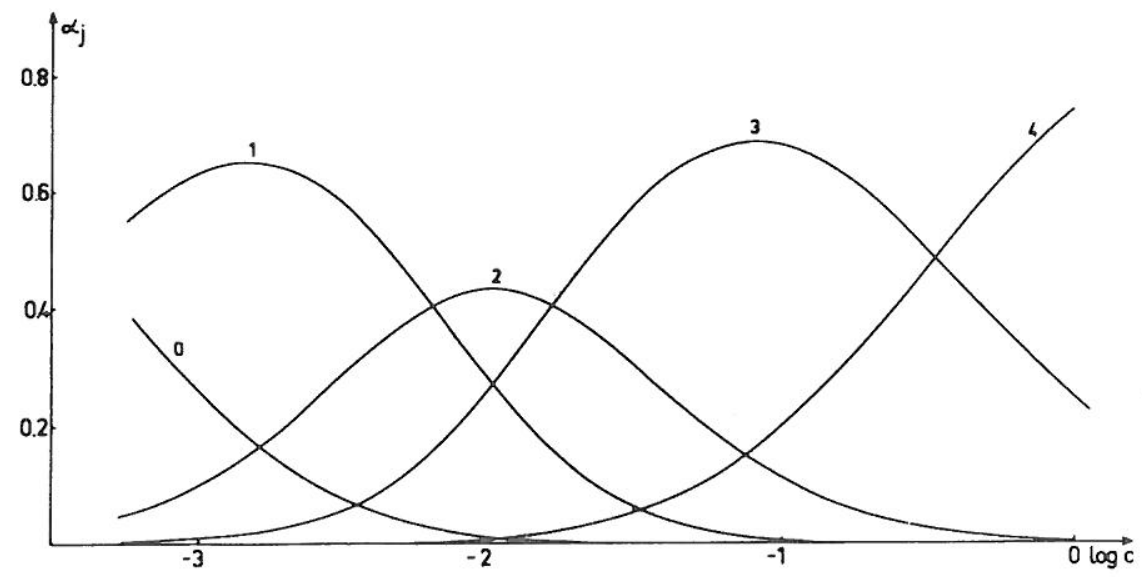

Fig. 3. Formation curves of the copper(II) chlorocomplexes in acetic acid. 


\section{REFERENCES}

Isosbestic points $(\lambda$ in $\mathrm{nm})$

Experimental

Calculated
302

357

437
303

354

\section{(g) Formation and structure}

Figure 3 represents the formation curves of the four copper(II) chlorocomplexes showing a very different pattern than either in water or in propylene carbonate. It is seen that for dilute solutions, chloride concentrations as low as $0.025 \mathrm{M}$, the fourth complex begins to form in appreciable quantities.

It is proposed that the tetrachlorocomplex has a $D_{2 d}$ symmetry in acetic acid. This can be inferred by the presence of a probable charge transfer band at $490 \mathrm{~nm}$ and the absence of any $d-d$ transition band below $1000 \mathrm{~nm}$. It is recalled that the ion of $D_{4 h}$ symmetry presents normally two bands in this region, one between 700 and $800 \mathrm{~nm}$ and the other between 900 and $950 \mathrm{~nm}$ whereas the configuration $D_{2 d}$ presents absorption maxima at $1100 \mathrm{~nm}$ and above. ${ }^{20}$ The presence of a band at $1080 \mathrm{~nm}$ and the absence of any band between 700 and $950 \mathrm{~nm}$ are favorable arguments for a $D_{2 d}$ structure of the tetrachlorocomplex in acetic acid.
'M. J. Schwing-Weill, Bull Soc. Chim Fr. 1973, 3, 823.

${ }^{2}$ M. A. Khan and M. J. Schwing-Weill, Inorg. Chem. 1976, 15, 2202

${ }^{3}$ C. Furlani and G. Morpurgo, Theor. Chim. Acto 1963, 1, 102 ${ }^{4}$ S. Manahan and R. T. Iwamoto, Inorg. Chem. 1965, 4(10), 1409. ${ }^{5}$ H. Hubacek, B. Stancie and V. Gutmann, Monatsh. Chem. $1963,94,1118$

${ }^{6}$ M. Baaz, V. Gutmann, G. Hampel and J. Masaguer, Monatsh Chem. 1962, 93, 1416.

${ }^{7}$ A. Foll, M. Ledemezet and J. Courtot-Coupez, J. Electroanal. Chem. 1972, 35, 41.

${ }^{8}$ J. P. Scharff, Bull. Soc. Chim. Fr. 1972, 1, 43.

${ }^{9} \mathrm{M}$. Elleb, J. Meullemeestre, M. J. Schwing and F. Vierling, Inorg. Chem., 1980, 19, 2699.

${ }^{10} \mathrm{~V}$. Gutmann, Coordination Chemistry in Non-Aqueous solvents, p. 30. Springer-Verlag, New York (1968).

"M. Elleb, J. Meullemeestre, M. J. Schwing and F. Vierling, Inorg. Chem. 1982, 21, 1477.

${ }^{12}$ R. P. Eswein, E. S. Howald, R. A. Howald and D. P. Keeton. J. Inorg. Nucl. Chem. 1967, 29, 437.

${ }^{13} \mathrm{~K}$. Sawada, H. Ohtaki and M. Tanaka, J. Inorg. Nucl. Chem. $1972,34,625$.

${ }^{14} \mathrm{~K}$. Sawada, H. Ohtaki and M. Tanaka, J. Inorg. Nucl. Chem. $1972,34,3455$.

${ }^{15}$ A. I. Popov, The Chemistry of Non-Aqueous Solvents (Edited by J. J. Lagowski, III), p. 243. Academic Press, New York (1970).

${ }^{16}$ K. Sawada and M. Tanaka, J. Inorg. Nucl. Chem. 1973, 35, 2455.

${ }^{17}$ S. Yamada, H. Nakamura and R. Tuschida, Bull. Chem. Soc. Jap. 1957, 30, 953

${ }^{18}$ R. L. Martin and A. Whitley, J. Chem. Soc. 1958, 1394.

${ }^{19}$ Z. Z. Hugus and A. A. El Awady, J. Phys. Chem. 1971, 75, 2954

${ }^{20}$ M. A. Khan, Thesis. Université Louis Pasteur, Strasbourg, France, 1975. 